\title{
COGNICIÓN: DENOMINADOR COMÚN PARA LOS ESTUDIOS DEL LENGUAJE EN LAS CIENCIAS COGNITIVAS*
}

\section{Carla Rimassa**}

\section{Resumen}

Se revisan propuestas sobre el vínculo lenguaje y cognición, comenzando con autores de fines de siglo XIX. Luego se desarrollan planteamientos de algunas disciplinas de las ciencias cognitivas. Los objetivos son resaltar la influencia interdisciplinar en la formación de los sustentos teóricos y diferenciar dos enfoques que conviven en la lingüística al alero de un denominador común, la visión cognitiva, a saber: la propuesta generativista y la lingüística cognitiva. Comparando ambas, se concluye que la noción sobre la cognición es, incluso, opuesta. Se aboga por la necesidad de diferenciar terminológicamente estas visiones cognitivas y se propone denominarlas, respectivamente: Independentista e Interdependentista (del sistema cognitivo).

Palabras clave: cognición, lenguaje, lingüística cognitiva, ciencias cognitivas, cognición corpórea.

\section{COGNITION: COMMON DENOMINATOR FOR THE STUDIES OF}

\section{LENGUAGE IN THE COGNITIVE SCIENCES}

\begin{abstract}
This paper describes a revision of proposals about the link between language and cognition, starting with some authors of the late 19th century. Subsequently, several approaches were developed about some disciplines of the cognitive sciences. The objectives are to highlight interdisciplinary influence on the formation of theoretical support and to differentiate between two approaches that coexist in linguistics under the auspices of a common denominator, cognitive vision, namely generative proposal and cognitive linguistics. After comparing both viewpoints, it can be concluded that ideas about cognition are even opposite. In this research, it is defended the need to differentiate terminologically between these cognitive visions and it is proposed to refer to them respectively as independent and interdependent (from the cognitive system).
\end{abstract}

Key words: cognition, language, cognitive linguistics, cognitive sciences, embodied cognition.

* Artículo derivado de la tesis doctoral de la autora (La capacidad de producir textos escritos sintácticamente complejos y su relación con la reserva cognitiva de los sujetos adultos que los producen) realizada con el aporte de la beca MECESUP2 PUCV/0606.

** Chilena, Fonoaudióloga, Doctora en Lingüística. Universidad de Valparaíso, Facultad de Medicina, Escuela de Fonoaudiología, Campus San Felipe. carlarimassa@gmail.com 


\section{Introducción}

La lingüística, como área científica para el estudio del lenguaje, comienza a desarrollarse a inicios del siglo XX. No obstante, en dichos años, de acuerdo a Álvarez (2010), el paradigma conductista imperaba en los ámbitos académicos y científicos, y los fenómenos de la conciencia no eran populares ni defendidos generalizadamente (al menos en Norteamérica). El conductismo dirige la atención, principalmente, sobre las características del objeto, los sistemas de refuerzo y las respuestas o conductas del individuo (Froufe, 2011). Así, durante la primera etapa del desarrollo de la lingüística, predominó un interés sobre la estructura y funciones del lenguaje, observando los elementos o componentes lingüísticos, sin considerar o dando escasa preponderancia a los procesos cognitivos involucrados en su procesamiento.

El paradigma cognitivo, que surge hacia fines de la tercera década del siglo pasado y adquiere mayor auge en los años sesenta, se opone a la propuesta conductista. El foco de atención cambia desde la conducta observable hacia la mente, un aspecto definido como caja negra en la postura anterior. La nueva propuesta destaca el aspecto racional y activo de las personas, relevando su capacidad de procesar e interpretar la información (Pons, 2013). La corriente cognitiva se presenta como una propuesta que intenta explicar cómo el ser humano interpreta el mundo que le rodea y cómo piensa ese mundo (Fiske \& Taylor, 1991). Sin embargo, Rodríguez-Consuegra (2004) señala que la revolución cognitiva basó algo de su éxito en los términos que encierra (cognitivo/ cognición), los cuales dieron la idea de abordar nuevos procesos, cuando en realidad se referían al pensamiento y al conocimiento que, agrega el autor, tenían diversas ciencias que los estudiaban. Ahora bien, tras 60 años de la extensión de la corriente cognitiva en la escena científica, se observa que mantiene su fuerza y vigencia. En este sentido, las ciencias cognitivas, conglomerado conformado por disciplinas tales como la psicología cognitiva, la antropología cognitiva, la neurociencia, la inteligencia artificial y la lingüística, entre otras, pueden ser definidas como un amplio campo multidisciplinar orientado a estudiar la cognición, la mente, los procesos psíquicos o cognitivos que subyacen a una determinada conducta (Varela, Thompson \& Rosch, 1991; Medina, 
2008; Thagard, 2008). Sin embargo, aunque aquellas disciplinas conviven en torno a la cognición, las aproximaciones o sustentos teóricos pueden distar mucho y ser, incluso, diametralmente opuestas.

Los objetivos de este trabajo son resaltar la influencia interdisciplinar en la formación de los sustentos teóricos y diferenciar los enfoques de la relación lenguaje-cognición en dos propuestas que conviven en la lingüística al alero de un denominador común, la visión cognitiva: la propuesta generativista y la lingüística cognitiva.

En la ciencia de los estudios del lenguaje se podrían dividir dos grandes corrientes respecto al vínculo lenguaje y cognición. Están aquellas surgidas en la mitad del siglo pasado, que observan al lenguaje como una facultad independiente de las funciones del pensamiento (Chomsky, 1957), frente a las propuestas que irrumpen en la década de 1970 y se consolidan en la siguiente, sosteniendo que el conocimiento lingüístico se adquiere de modo similar a la forma requerida para otros tipos de conocimiento (Croft \& Cruse, 2008, Fernández-Jaén, 2010). En otras palabras, en el primer enfoque, ciertos aspectos del lenguaje (la sintaxis) se asumen como innatos, autónomos e independientes de las otras capacidades cognitivas (Chomsky, 1957, 1959, 1965, 1975, 1985, 1995; Pinker, 1995; Hauser, Fitch \& Chomsky, 2002; Fitch, Hauser \& Chomsky, 2005; Pinker \&, Jackendoft, 2005). Mientras, en la segunda tendencia, el lenguaje se considera un fenómeno mental interrelacionado e interdependiente de otras capacidades del sistema cognitivo global (Lakoff, 1987; Langacker, 1987; Talmy, 1988; Turner, 1990,1994; Hilferty, 1993; Fauconnier \& Turner, 1998; Kövecses \& Radden, 1998; Cuenca \& Hilferty, 1999; Croft \& Cruse, 2008; Evans \& Green, 2006; Geeraerts, 2006; Ibarretxe \& Valenzuela, 2012; Valenzuela, Ibarretxe \& Hilferty, 2012).

En lo que sigue del trabajo, se describen algunas propuestas precursoras de la relación lenguaje y cognición de investigadores de fines de siglo XIX e inicios del XX en el ámbito europeo. Luego, se detallará la propuesta modular de la sintaxis y algunas críticas que ha recibido sobre la especificidad genética y la modularidad. A continuación, se presentan los aportes de las neurociencias y la postura de la lingüística cognitiva. Se concluirá este trabajo con las reflexiones finales. 


\section{Estudios Precursores del Vínculo Lenguaje y Cognición}

La relación entre lenguaje y cognición, directa o indirectamente, ha sido un tema largamente discutido en diferentes disciplinas científicas desde los antiguos filósofos hasta la fecha, porque, según expone HernándezPiña (1980:69), "el papel que el lenguaje desempeña en nuestro desarrollo cognitivo ha sido y continúa siendo un tema polémico". En otras palabras, aún con la larga data de referencias a dicho vínculo, este sigue siendo un tema vigente, abierto y profusamente investigado.

Desde un punto de vista biológico, los planteamientos de Darwin (1859) sostienen que el lenguaje es un instinto de la especie humana, regido por los mecanismos de regulación sexual (vocalizaciones para apareamiento), que habría evolucionado gradualmente, como también lo hicieron otras respuestas adaptativas producto de aspectos innatos y aprendidos (Lorenzo, 2009). Paralelamente, el neurólogo, anatomista y antropólogo francés, Broca (1861), tras la autopsia efectuada al cerebro de un paciente con alteración del nivel expresivo y mantención de la facultad comprensiva del lenguaje, da cuenta de sus hallazgos en la sociedad de antropología de París, siendo uno de los primeros investigadores en señalar la injerencia y especificidad del funcionamiento cerebral sobre el lenguaje. El cerebro de dicho paciente presentaba una lesión en la tercera circunvolución del lóbulo frontal izquierdo. Su descubrimiento abrió el amplio campo de investigación destinada a conocer la actividad del cerebro, asociada con las capacidades lingüísticas. La zona frontal señalada es actualmente conocida como área de Broca (Sagan, 1981; Foucault, 2005; Freberg, 2010).

Por otra parte, hacia mediados de la tercera década del siglo pasado, en el marco de teorías psicológicas y biologisistas, en Suiza, Piaget (1923, 1924) incorpora elementos activos del sujeto sobre los objetos y los asocia con el desarrollo del pensamiento y el lenguaje. La obra piagetana expone que la actividad sensorio-motora precede a la representación y a las formas operatorias del pensamiento. Además, en este enfoque, el desarrollo cognitivo es un proceso que se da por etapas y evoluciona a partir de esquemas y representaciones mentales que se complejizan hacia el logro de un razonamiento lógico-matemático. 
Según Piaget (1923), la etapa comprendida entre el nacimiento y la adquisición dellenguaje (12-18 meses) es decisiva en la evolución psíquica. Primero, el menor refiere todas las cosas a sí mismo; en cambio, con la obtención del pensamiento y el lenguaje, el sujeto pone su cuerpo como un elemento entre otros, exterior a sí mismo. La representación mental, que está basada en procesos perceptivos, es definida como "la reunión de un significador que permite la evocación de un significado procurado por el pensamiento" (Piaget, 1961, p. 370). El lenguaje es el instrumento por el cual las representaciones se forman y se socializan, donde "el desarrollo del pensamiento posibilita el empleo de signos verbales" (371). En este sentido, el estudioso suizo señala que "la adquisición del lenguaje está subordinada al ejercicio de una función simbólica que se apoya en la imitación y el juego" (p. 8), agregando que en la base del proceso de desarrollo del pensamiento existen dos mecanismos indisociables entre sí: el conocimiento físico de observación e interacción con los objetos y la abstracción lograda por la coordinación de sus acciones para integrar o asimilar ambos en esquemas de acción, adaptarlos, transformarlos o reestructurarlos en nuevos esquemas (Piaget, 1924).

De acuerdo a lo expuesto anteriormente, se aprecia que en esta línea cognitiva el pensamiento se desarrolla antes que el lenguaje; es decir, ambos procesos tendrían raíces de adquisición diferentes. Es más, el desarrollo del pensamiento posibilita el desarrollo del lenguaje, el cual es dependiente del nivel y etapa cognitiva individual. Cabe destacar la interacción del individuo con los objetos como base del desarrollo cognitivo. Lo anterior alude a lo que actualmente se denomina cognición corpórea (sentidos, percepción, experiencia y acción). Este constituye un tópico fundamental en la noción de cognición asumida en la lingüística cognitiva, aunque en ella no se hace mención expresa a la propuesta piagetana, como se verá más adelante.

Por otra parte, al este de Europa, en Rusia, y con diferencias respecto a la visión anterior, Vygotsky $(1929,1934)$ afirma que el pensamiento y el lenguaje son funciones mentales superiores que se desarrollan en continua influencia recíproca, con sustrato filo y ontogenético diferente y que, en algún momento, estas líneas se encuentran, entonces el pensamiento se verbaliza y el lenguaje se racionaliza (Vygotsky, 1934). Además, este pensador considera al lenguaje como herramienta que 
posibilita la codificación de la cultura experimentada por el individuo en la sociedad; por lo tanto, es un sistema semiótico que permite el desarrollo humano. Vygotsky (1934) argumenta que la función psíquica superior en el desarrollo del niño aparece primero como una actividad colectiva o función interpsíquica, que luego se vuelve una actividad individual de pensamiento interior o función intrapsíquica. La teoría histórico-cultural de la génesis y del desarrollo de los procesos psicológicos superiores, en palabras de Lucci (2006), describe "el funcionamiento intelectual humano que incluye tanto la identificación de los mecanismos cerebrales subyacentes a la formación y desarrollo de las funciones psicológicas, como la especificación del contexto social en que ocurrió tal desarrollo" (Lucci, 2006, p. 5).

En síntesis, se observa que las ideas vygotzkyanas introducen el aspecto social como fundamento del desarrollo cognitivo, donde pensamiento y lenguaje son presentados explícitamente como funciones superiores interdependientes y este último se constituye en una herramienta de transmisión cultural. En otras palabras, en esta teoría todas las funciones mentales superiores son una interiorización del orden social. Esta propuesta tiene absoluta vigencia, aunque estos planteamientos no llegaron al mundo occidental generalizado sino 30 años después de su publicación original, con la traducción al inglés de la obra póstuma Pensamiento y Lenguaje ${ }^{1}$.

Ahora bien, en el otro extremo europeo, en Inglaterra, Craik (1943), filósofo, psicólogo y fisiólogo, postuló un modelo de funcionamiento neurológico a la base del pensamiento y la significación, a saber: que la estimulación de los órganos sensitivos se traslada a través de patrones neuronales que se depositan o reservan en el cerebro. De acuerdo a este investigador británico, por medio de los procesos de razonamiento se producen otros patrones neuronales que reconvierten la excitación de los órganos motores, cuyo proceso resultante es similar al generado por la causa real. Este razonamiento, según Craik, alude al lenguaje, el cual conduce la entrada y salida de símbolos y evoluciona por las reglas que gobiernan el uso de palabras, de tal manera que el pensamiento puede producirse en paralelo a él.

1 La primera traducción de esta obra al inglés fue en 1962 y al español en 1964. En este trabajo se usó la traducción de Itzigsohn (1995). 
Se observa que en la propuesta craikiana aparece un elemento que se asocia, nuevamente, con la cognición corpórea, la formación de patrones cerebrales a partir de la experiencia de los órganos de los sentidos que se reactivan con el lenguaje u otros procesos cognitivos. Es decir, el lenguaje se presenta como interdependiente de la función cognitiva y como un instrumento de transmisión simbólica.

En síntesis, de acuerdo a lo expuesto en párrafos anteriores, antes de que comenzara el siglo pasado dos importantes figuras del quehacer científico habían instalado a lo menos dos nociones básicas que están presentes en las actuales discusiones del vínculo cognición y lenguaje, a saber: el lenguaje como conducta innata y su dependencia con áreas específicas del cerebro. No obstante, en lingüística, estas ideas no fueron parte del debate ni incorporadas sino 70 años después (con modificaciones), en algunos fundamentos de la propuesta generativista. Asimismo, desde otras disciplinas y con notable antelación a su abordaje y discusión en la lingüística, se instalaron propuestas que abordaron el vínculo cognición y lenguaje, proponiendo que estos son fenómenos relacionados $\mathrm{y}$, aunque algunos autores los señalen con adquisición paralela, son descritos como interdependientes y donde aspectos sociales, cognitivos, vivenciales, sensoriales y perceptivos forman un intrincado andamiaje en la formación del conocimiento.

\section{Algunos Enfoques de las Ciencias Cognitivas para la Relación Lenguaje y Cognición}

\subsection{Propuesta Generativo Transformacional}

En los inicios del desarrollo de la lingüística predominó el enfoque conductista, por lo que existió, preferentemente, un interés sobre la estructura, componentes y funciones del lenguaje, dando escasa o nula cabida a los procesos cognitivos involucrados en la producción. Sin embargo, a mediados de la década de 1950 aparece una propuesta cuyos planteamientos causaron una revolución y fomentaron un nuevo paradigma dentro de este campo investigativo: el generativismo chomskyano. Chomsky (1957) puntualiza que el refuerzo, argumentado por el conductismo para la adquisición del lenguaje, era insuficiente para explicar la infinitud discreta de los enunciados, la rapidez de aprendizaje de la lengua y el hecho que en todas las lenguas existieran 
principios estructurales comunes, señalando que las personas poseen una competencia que les permite proferir oraciones con sentido porque dominan una serie de reglas de generación. Así, Chomsky (1957) asume que el conocimiento de la lengua por parte de un sujeto es su competencia gramatical, que está representada mentalmente. Por ello, el objetivo del estudio del lenguaje, opuesto a la etapa anterior, pasa de lo observable a lo no observable. Es decir, se releva la importancia de los procesos mentales subyacentes a la aplicación de reglas gramaticales, instaurándose una visión cognitiva, aunque clásica, la cual consiste en que "todos los sistemas procesadores de información, incluido el cerebro humano, comparten los mismos principios. A partir de la analogía entre la computadora y el cerebro, se consideró apropiado estudiar la mente como si se tratara de un software" (Fierro, 2011, p. 519).

De acuerdo al generativismo, el conocimiento lingüístico se distingue del uso y del significado y se lo asume como un dominio específico, cuyo componente central es la sintaxis (Eguren \& Fernández, 2003). Es así que Chomsky (1959) plantea estudiar al lenguaje como un órgano biológico y lo propone como órgano mental. Por ello, defiende la existencia de un Dispositivo para la Adquisición del Lenguaje (DAL). Este módulo mental realiza las representaciones lingüísticas en forma autónoma; es decir, independiente del pensamiento; está premodelado de forma innata y detenta características, propiedades y pautas de desarrollo específicas y universales (Chomsky, 1975). En otras palabras, existiría “[...] un sistema diferenciado de la mente / cerebro con un estado inicial (S0) común a toda la especie y, al parecer único en aspectos esenciales [...]" (Chomsky, 1985, p. 41). El autor argumenta que esta facultad de las personas, frente a una experiencia apropiada, pasa del estado inicial a un estado relativamente estable (Ss), cuya modificación es periférica, pues incorpora una lengua-I. Según Berwick, Chomsky y Piatelli $(2008,2013)$ este postulado significa que "there is in the general initial cognitive state a subsystem (that we are calling [UG] for language) which has a specific integrated character and which in effect is the genetic program for a specific organ" (Berwick et al., 2013, p. 37). De esta forma, los postulados chomskyanos, que inicialmente se centraban solo en la sintaxis, fueron complementándose con la incorporación de aspectos semánticos, fonológicos como también genéticos. Chomsky (1995) señala que el lenguaje, además de ser un estado de la mente de los seres humanos, es una propiedad del código genético de los mismos. 
Paralelamente, Pinker (1995) -un discípulo del gestor de la Gramática Universal (GU) -, amplía los planteamientos de su maestro, proponiendo que la selección natural puede explicar el origen del órgano del lenguaje chomskiano. Es decir, aquellos individuos que a lo largo de la evolución del ser humano poseyeron una mejor capacidad para el lenguaje son los que proliferaron y transmitieron dicha capacidad a su descendencia a través de los genes; por lo tanto, la capacidad lingüística sería genética. El autor especifica que un gen del lenguaje o de la gramática "podrían definirse como secuencias de ADN que codifican proteínas, o desencadenan la transcripción de proteínas, en determinados momentos y lugares del cerebro" (Pinker, 1995, p. 352). Aunque el psicólogo agrega que "no hay modo de verificar directamente la existencia de genes gramaticales en los seres humanos" (353), más bien, complementa el autor, el lenguaje "debe de estar radicado en alguna parte del cerebro, y los circuitos en los que se asienta han tenido que recibir sus capacidades de los genes responsables de su existencia" (327).

En síntesis, para este autor el instinto del lenguaje está determinado genéticamente, es consecuencia de la selección natural que posibilitó el surgimiento de un órgano ubicado en el cerebro y que permitió la supervivencia de quienes lo poseían.

Por otra parte, Hauser et al. (2002) proponen que la facultad del lenguaje (FL) tendría dos componentes: una facultad en el sentido amplio (FLB) y otra en el sentido estrecho (FLN). La FLB está conformada por sistemas de interfaz como el sensorio-motor, el conceptual-intencional y por un núcleo, que es el sistema computacional recursivo, la FLN. Es decir, este último componente corresponde a un conjunto de operaciones sintácticas abstractas de las que derivan las oraciones gramaticales. Por lo tanto, la FLN está formada solo por los mecanismos de recursividad, es modular respecto del sistema cognitivo general, está biológicamente condicionada, es exclusivamente humana y posee las características enunciadas en las propuestas chomskyanas iniciales.

Finalmente, los postulados generativistas, si bien representaron el punto de partida para el cambio de paradigma existente en la lingüística que anteriormente escindía el fenómeno mental y se focalizaba en el texto escrito, no eran temas inexplicados fuera de ella, pues la injerencia mental, cognitiva o cerebral sobre los procesos lingüísticos había sido abordada en otros ámbitos, pero no se había difundido en esta ciencia. Así, 
instaurar el foco en lo mental y definir el lenguaje como una capacidad innata que presenta un órgano específico, modular e independiente de las funciones del pensamiento y que está genéticamente determinado, fueron, entre otros aspectos, planteamientos que revolucionaron este campo investigativo. Sin embargo, la modularidad y la determinación genética son aspectos no exentos de crítica.

\subsubsection{Críticas a la Propuesta Generativista}

Chomsky (1980) argüía que el funcionamiento del hígado está predeterminado genéticamente, indicando que de igual forma el lenguaje es parte del programa genético del cerebro y que éste podía estudiarse como cualquier otro órgano. En este sentido, se aprecia que el autor se refería al cerebro como a un órgano de similar complejidad que otros del cuerpo humano. Changeux (1980) aclara que existen a lo menos dos diferencias radicales entre las células del hígado y las del cerebro. La primera es que la célula nerviosa es infinitamente más compleja que el hepatocito. La segunda diferencia es que la capacidad de aprender está determinada, precisamente, por millones de interconexiones celulares que la neurona es capaz de realizar y las células del hígado no pueden lograr.

Por otra parte, respecto de un gen específico para el lenguaje, Hilferty y Villaroya (2002) critican dicha idea y sostienen que los genes no cuentan con los recursos representativos para especificar rasgos fenotípicos, sino que codifican la estructura primaria de las proteínas. En otras palabras, la expresión de un gen es el resultado de una serie de complejos procesos y, en general, la aparición del fenotipo es el resultado de múltiples genes, junto a la influencia del ambiente. En línea con lo anterior, Benítez-Burraco (2005) señala que "resulta imposible reducir la complejidad del sustrato neurológico del lenguaje (y, por extensión, de la cognición humana) a la actividad de un único gen" (p. 42). La idea es reforzada por Stromswold (2008) quien sostiene que el lenguaje envuelve distintas capacidades cognitivas, las cuales poseen sustentos genéticos y neurológicos diferenciados. Asimismo, Beteta (2003) aclara que se ha intentado conocer la incidencia genética en afecciones del sistema cognitivo; sin embargo, aún no es posible "establecer las bases genéticas de las funciones cognitivas" (p. 341). Lo anterior deriva de la magnitud de la tarea, pues el genoma humano está conformado por 2.000.000.000 
de nucleótidos de ADN. El 2\% de los genes tiene proteínas codificadas, otro 58\% no está codificado y "el 40\% no tiene significado conocido" (p. 336).

Ahora bien, en relación a las críticas sobre la modularidad chomskyana, Zapata (2009) explica que el estudio del curso del linaje homo muestra un proceso evolutivo cerebral que posiblemente se produjo para "generar un proceso cognitivo cada vez más complejo [...] como estrategia bastante efectiva de supervivencia para una especie físicamente muy débil" (p. 111). Por ello, señala Mithen (1996), al estudiar la filogenia homo, desde el homo más primitivo hasta la aparición del homo sapiens sapiens, se observa que los ancestros más primitivos presentaban tres grandes módulos mentales separados: uno técnico, otro de conocimiento del mundo natural y otro social. La paleontología propone que la mente moderna viene fraguándose hace 3.800.000.000 años, pero es desde hace 60.000 años que se puede hablar de cognición moderna o cognición simbólica (Mithen, 1996). Se considera que "(el lenguaje) facilitó la integración de los tres módulos, lo que permitió esta forma de generación de una de las características de la mente moderna, la fluidez cognitiva" (Zapata, 2009, p. 113). En otras palabras, cuando se alcanza la cognición simbólica, el ser humano logra la fluidez cognitiva que "le permite integrar por primera vez el mundo social con el mundo natural” (p. 116). Es más, la fluidez en la interconexión de información diversa y el lenguaje instauran formas más complejas de percibir y de conocer el mundo, lo cual caracteriza a la mente moderna (Wong, 2005). Esta forma de cognición humana es la que ha posibilitado las respuestas que propiciaban comportamientos adaptativos, los cuales permitieron, a unos más que a otros, la supervivencia de la especie (Bearman, 2007).

De acuerdo con lo expuesto en este apartado, se observa que las teorías se construyen, reconstruyen y confrontan porque especialistas de distintas áreas trabajan de modo interdisciplinar. En este caso, las críticas expuestas evidencian aportes de la biología, neurología, psicología y antropología, entre otras disciplinas, donde la incorporación de técnicas de neuroimagen y otros avances tecnológicos de las neurociencias han ampliado el conocimiento sobre el vínculo lenguaje-cognición, aspecto base en la revisión de este trabajo. 


\subsection{Aportes de las Neurociencias y la Lingüística Cognitiva}

\subsubsection{Aporte de las Neurociencias}

Los hallazgos neurológicos señalan que el $25 \%$ de la neocorteza cerebral está encargada de responder en forma sensitiva y motora a los estímulos, en tanto que el $75 \%$ restante se encarga de atender, reconocer, planificar y experimentar respuestas a los estímulos (Purves, Agustines, Fitzpatrick, Katz, Lamantia \& McNamara, 2001). Dichas funciones son denominadas cognición (De la Barrera, Donolo \& Rinaudo, 2010). En tanto que Kolb y Whishaw (2009) llaman funciones cognitivas, entre otras, a la memoria operativa, la atención, el reconocimiento de caras y objetos, las asociaciones sensoriales, operaciones lógico-matemáticas, la planificación y organización de movimientos, la toma de decisiones, el cálculo y el lenguaje. En esta línea, González (2006) expone que la cognición es un campo donde se trenzan tres componentes: la percepción, la categorización y la conceptualización. El autor señala que estos tres procesos se interrelacionan, dando como resultante el proceso cognitivo general.

Considerando lo descrito en el párrafo precedente, se observa que el lenguaje no se describe como un proceso independiente de otras funciones cognitivas, sino como un fenómeno que forma parte del sistema cognitivo global. En este sentido, De la Barrera et al. (2010) señalan que la cognición no solo implica una serie de funciones mentales interconectadas, sino que, además, es un proceso de interacción activa con el ambiente, que produce conocimiento y posibilita al individuo la adaptación al medio. Conocer, de acuerdo a estos autores, implica procesos de memoria, funciones ejecutivas, atención, concentración, capacidad de organización, planificación y lenguaje, como "cuestiones claves para el normal funcionamiento en la vida diaria" (De la Barrera et al., 2010, p. 35). En línea con lo anterior, Varela (2001) señala que la cognición es la resultante de un fenómeno complejo producto de la interacción del cuerpo y la realidad y que a nivel neurológico no es la suma de procesos locales sino que un fenómeno emergente global. Esto último posibilita la aparición de una unidad coherente e integrada, que es una unidad cognitiva y cuyo status es ontológicamente diferente. Esta concepción de la cognición, denominada cognición corpórea (embodied cognition), es fruto de continuos hallazgos en las neurociencias sobre los procesos mentales y su vínculo con el entorno. 
La cognición corpórea es un nuevo paradigma, contrario a la visión simbólica tradicional, cuyo inicio podría situarse en torno a la confluencia de publicaciones como Methaphors we live be (Lakoff \& Johnson, 1980), Women, fire, and dangerous things (Lakoff, 1987), The body in the mind (Johnson, 1987) y The Embodied Mind: Cognitive Science and Human Experience (Varela, Thompson \& Rosch, 1991), entre otras. Ahora bien, esta noción sobre la cognición evidencia un variado espectro de estudios, donde el enfoque de cognición situada y el de cognición enactiva aparecen, de acuerdo con Wilson (2002), como los mejor evaluados en términos de utilidad y aplicabilidad. No obstante, todos ellos, de acuerdo con Damasio (1994), reconocen un punto de partida común, a saber: considerar que la mente no trabaja en abstracto (símbolos) sino que existe un cuerpo que necesita una mente para efectuar su función. Vale decir, en este paradigma, el cuerpo no se considera un contenedor de un cerebro que conoce o el soporte para una mente, sino que un medio vinculante con el entorno que posibilita la cognición. Dicho planteamiento implica que los cambios del entorno producirán efectos en el cuerpo, los que, a su vez, modificarán la estructura representacional del ser humano (Varela, 1989, 1996, 2001; Varela et al., 1991; Damasio, 1994; Begley, 2008). El planteamiento esbozado anteriormente queda justificado en la siguiente reflexión: “[...] si lo primero para lo que se desarrolló evolutivamente el cerebro es para asegurar la supervivencia del cuerpo propiamente dicho, entonces, cuando aparecieron cerebros capaces de pensar, empezaron pensando en el cuerpo" (Damasio, 1994, p. 213).

En este sentido, De Vega (2005) señala que el enfoque corporizado de cognición se constituye en un aporte en la comprensión de la mente y el lenguaje, agregando que este enfoque es "un cuerpo teórico elaborado a partir de aportaciones multidisciplinares de muchos autores [...] En los últimos años la noción de corporeidad ha dejado de ser una mera especulación de salón para fundamentarse en rigurosos estudios experimentales" (p. 172-173).

En resumen, se observa que en los estudios de la neurociencia se asume una visión de cognición experiencialista, fundamentada en los sentidos, la percepción y lo motor, y donde el lenguaje es considerado un fenómeno interdependiente del sistema cognitivo global. Este enfoque de cognición es el que asume la lingüística cognitiva. 


\subsubsection{Propuesta de la Lingüística Cognitiva}

Una aproximación al estudio del lenguaje dentro de las ciencias cognitivas es la iniciada por Lakoff y Johnson (1980), quienes sostienen que nuestro sistema conceptual cotidiano es fundamentalmente de naturaleza metafórica. Con ello estos autores destacan que,

The concepts that govern our thought are not just matters of the intellect. They also govern our everyday functioning, down to the most mundane details. Our concepts structure what we perceive, how we get around in the world, and how we relate to other people. Our conceptual system thus plays a central role in defining our everyday realities. (p. 3).

En general, la propuesta de la lingüística cognitiva debe asumirse como "un movimiento lingüístico que concibe al lenguaje como un fenómeno integrado dentro de las capacidades cognitivas humanas" (Ibarretxe \& Valenzuela, 2012, p. 47). De acuerdo con Geeraerts (2006) "theories in linguistics tend to be fairly insular affair: each theoretical framework tends to constitute a conceptual and sociological entity in its own right $[\ldots]$ takes the form of archipelago rather than an island" (p. 2), porque no se trata de una teoría particularmente bien definida, sino de un marco flexible. Ahora bien, concordando con los autores precedentes, Croft y Cruse (2008) agregan que este marco disciplinar asume que el lenguaje no es una facultad cognitiva autónoma, que la gramática implica siempre una conceptualización y que el conocimiento del lenguaje surge por el uso.

De acuerdo a lo señalado anteriormente, la lingüística cognitiva, al asumir como premisa básica que el lenguaje es una capacidad integrada en la cognición general, se está distanciando de las posturas que lo describen como un módulo autónomo. Asimismo, se inscribe en la búsqueda de las conexiones de la facultad lingüística con otras facultades cognitivas (Ibarretxe \& Valenzuela, 2012). En este sentido, Evans y Greens (2006) exponen que la razón más importante detrás de los estudios en esta área es que se asume que el lenguaje refleja patrones del pensamiento. En otras palabras, "to study language from this perspective is to study patterns of conceptualisation. Language offers a window into cognitive function, providing insights into the nature, structure and organization of thoughts and ideas" (p. 5). 
Esta visión cognitiva concibe al lenguaje como un vehículo de transmisión de significados y de la conceptualización del mundo. El lenguaje se considera una función mental dependiente del sistema cognitivo global, que se ve influenciada por factores externos (Lakoff, 1987). Asimismo, se asume la cognición como proceso corpóreo y motivado por la experiencia. Además, se considera que el ser humano organiza su entorno en función de las experiencias o vivencias del individuo (Lakoff, 1987; Langacker, 1987; Talmy, 1988; Turner, 1990,1991; Hilferty, 1993; Kövecses \& Radden, 1998; Cuenca \& Hilferty, 1999; Lakoff \& Johnson, 1999; Croft \& Cruse, 2008; Evans \& Green, 2006; Geeraerts, 2006; Ibarretxe \& Valenzuela, 2012; Valenzuela et al., 2012). Por ello, Ibarretxe y Valenzuela (2012) señalan que el lenguaje es

un fenómeno integrado dentro de las capacidades cognitivas humanas [...] la capacidad lingüística no se puede entender de manera autónoma e independiente, se hace entonces necesario explorar las relaciones entre el lenguaje y otras facultades cognitivas como la percepción, la memoria o la categorización, en busca de mecanismos cuyo funcionamiento pueda aportar explicaciones y soluciones al problema de cómo funciona realmente el lenguaje. (p. 48-9).

En tanto, de acuerdo a Cuenca y Hilferty (1999), la categorización es un proceso de la cognición que posibilita la comprensión del mundo. En este sentido, según los autores, el mundo existe en la medida que es experimentado y reflexionado por un individuo, quien organiza la variada realidad del mundo a partir de los procesos de generalización y discriminación que se traduce en categorías cognitivas, definidas como "conceptos mentales almacenados en nuestro cerebro" (p. 33).

De acuerdo a Lakoff (1987), los procesos de razonamiento en general, tanto como las categorías conceptuales en particular, tienen cuatro propiedades: son corporizadas, imaginativas, utilizan propiedades gestálticas y presentan un procesamiento ecológico, porque todas las funciones cognitivas interactúan y se interrelacionan entre sí.

La importancia del vínculo lenguaje y cognición, según Croft y Cruse (2008), se resume en que,

los hablantes conceptualizan la experiencia con el propósito de comunicarlo a otras personas, lo que cuenta, a su vez, con 
propósitos socio-interactivos más amplios [...] los lingüistas cognitivos tienen la posibilidad de contribuir al desarrollo de una teoría del lenguaje que vaya más allá de la cognición, pero también al de una teoría de la cognición que vaya más allá del lenguaje. (p. 423).

En síntesis, de acuerdo a este modelo, la cognición es un proceso corpóreo y el lenguaje es motivado por la experiencia, es inherentemente simbólico, es un instrumento de transmisión de conceptualizaciones o significados y es una capacidad cognitiva inseparable de las restante funciones superiores, porque se considera que ellas se implican mutua y globalmente y sus funciones cognitiva y comunicativa no pueden separarse. Asimismo, este enfoque aboga por el dinamismo e interacción entre sus componentes y, dado que todos los aspectos del lenguaje son simbólicos, se defiende la inseparabilidad de los niveles lingüísticos.

Finalmente, al comparar ambas posturas expuestas, la generativista y la lingüística cognitiva, se observa que la noción de cognición y su vínculo con el lenguaje, aún coexistiendo bajo el paraguas cognitivo como denominador común, presentan profundas diferencias. Así, las propuestas chomskyanas, adoptan el cognitivismo clásico, donde la cognición es amodal, fundamentada en un procesamiento de información de tipo simbólica y proposicional, como las que utilizan los programas informáticos. Así, se trata de "representaciones cognitivas inobservables, es decir, por ser abstractas, son inaprehensibles por medio de los sentidos" (Weerth, 1998, p. 60). Esta corriente asume que la mente funciona como un computador "con código simbólico, digital, de reglas e instrucciones, que se aplican sobre una base de 'datos', de conocimiento, también representado formalmente" (Gomila, 2009, p. 49). Ahora bien, en relación al lenguaje, esta propuesta lo asume como un módulo mental autónomo o independiente del pensamiento, que está premodelado de forma innata y con características de desarrollo específicas y universales. Por ello se propone identificarla como visión independentista. En cambio, la lingüística cognitiva adopta una visión cognitiva paralela y diferente de la anterior, denominada cognición corpórea. Esta es una postura modal, es decir, se sustenta en la percepción, en los órganos de los sentidos y en la función motora, porque es fundamentalmente experiencialista. Además, el lenguaje se asume como una función que depende y se interrelaciona con las restantes funciones del sistema cognitivo global 
y donde los niveles lingüísticos también están interconectados. Por lo tanto, se propone identificarla como visión interdependentista, más dinámica y abierta que la anterior y donde el entorno, lo social y corporal se entrelazan para generar un producto: la cognición.

\section{Reflexiones Finales}

Un primer aspecto que se resalta en este trabajo es que, tempranamente (fin de siglo XIX e inicios del siglo XX), desde otras disciplinas (biología, psicología, neurología, fisiología y otras) se instalaron propuestas que incorporaron aspectos sociales, individuales y del entorno para abordar la relación cognición y lenguaje, como también expusieron planteamientos que presentaban a dichos procesos como fenómenos interrelacionados, aunque cada uno de ellos pudiera tener procesos de adquisición diferente. Sin embargo, ello tardó mucho en ser incorporado en el análisis, estudios, discusión o debate de la lingüística.

Por otra parte, ante la interrogante que motivó este trabajo, se observa que la respuesta a cuál es el enfoque al que adhiere un investigador cuando asume tener una visión cognitiva del lenguaje, no es posible contestar, en primera instancia, sin un término diferenciador. Por ello se generó este espacio de exposición, discusión y reflexión, ya que, según lo descrito, las dos propuestas de estudios del lenguaje que coexisten en las ciencias cognitivas y que fueron aquí tratadas presentan visiones cognitivas y de la relación lenguaje-cognición que son evidentemente contrapuestas. En este sentido, las denominaciones "generativista" y "lingüística cognitiva" no son diferenciadoras, porque ellas aluden al marco teórico general y no a la visión cognitiva en particular.

Ahora bien, de acuerdo a lo revisado, se destacan tres diferencias básicas entre los dos enfoques expuestos; estas son: el foco de interés, el tipo de vínculo lenguaje-cognición y la noción de cognición. En relación a la primera, uno de los tópicos principales del generativismo es presentar un modelo de la adquisición del lenguaje, mientras que entre los aspectos centrales de la lingüística cognitiva se encuentra el estudio de los fenómenos que subyacen al procesamiento del lenguaje en el uso. En torno al segundo diferenciador, el vínculo lenguaje-cognición, la propuesta generativista asume que la facultad del lenguaje es modular respecto del sistema cognitivo general, un módulo mental autónomo o independiente del pensamiento, definido como un sistema computacional 
recursivo, que está formado por un conjunto de operaciones sintácticas abstractas, exclusivamente humano y biológicamente condicionado; en cambio, la lingüística cognitiva considera al lenguaje como una función dependiente e interrelacionada con el sistema cognitivo global, señalando que este último tiene un funcionamiento ecológico. Además, aboga por la interacción y dinamismo componencial, puesto que todos los aspectos del lenguaje son simbólicos y, por ello, releva la inseparabilidad de los niveles lingüísticos. En tercer lugar, y acentuando las diferencias entre ambas posturas, está la noción de cognición. El generativismo asume una noción clásica y amodal; en cambio, en la lingüística cognitiva la cognición es corpórea; por lo tanto, modal. Vale decir, la primera prescinde de la experiencia, de la acción de los órganos de los sentidos y de la función perceptiva y motora como factores en los que se asienta el proceso cognitivo, mientras la segunda se basa en ellos.

Considerando las diferencias anteriormente expuestas, este trabajo insiste en la necesidad de precisar terminológicamente las visiones cognitivas sobre el lenguaje. Por ello, se han propuesto y usado aquí dos diferenciadores terminológicos: enfoque cognitivo independentista y enfoque cognitivo interdependentista. Independentista, porque dicho enfoque defiende la existencia de un componente modular del lenguaje que es independiente del sistema cognitivo. Interdependentista, en tanto, alude al enfoque opuesto, donde el lenguaje es una función cognitiva dependiente e interrelacionada con el sistema cognitivo global y cuyo procesamiento evidencia una estructura ecológica.

Finalmente, un aspecto común a los dos enfoques es la interdisciplinaridad. Se hace evidente que la cooperación de diferentes especialistas es condición necesaria y fundamental para la construcción de saberes y para la formación de sustentos teóricos más robustos y más amplios. Asimismo, se observa que incorporar o extrapolar métodos, hallazgos y tecnologías desde otras áreas hacia las ciencias del lenguaje se constituye en un factor que enriquece las propuestas y horizontes investigativos de estas ciencias. 


\section{Referencias Bibliográficas}

Álvarez, C. (2010). La relación entre lenguaje y pensamiento de Vigotsky en el desarrollo de la psicolingüística moderna. Revista de lingüística teórica y aplicada, 48(2), 13-32.

Bearman, C. (2007). Modern cognition in absence of working memory. Does working memory account of Neandertal cognition work? Journal of Human Evolution, 52 (6), 702-706.

Begley, S. (2008). Entrena tu mente. Cambia tu cerebro. Bogotá: Norma.

Benítez-Burraco, A. (2005). FOXP2: del trastorno específico a la biología molecular del lenguaje. I. Aspectos etiológicos, neuroanatómicos, neurofisiológicos y moleculares. Revista de Neurología, 40(11), 671-82.

Berwick, R., Chomsky, N. \& Piatelli, M. (2008). Poverty of the stimulus revisited: Recent challenges reconsidered. En B. Love, K. McRae \& V. Sloutsky (Eds.), Proceedings of the 30th Annual Conference of the Cognitive Science Society (pp. 383-384). Austin: Cognitive Science Society.

Berwick, R., Chomsky, N. \& Piattelli, M. (2013). Poverty of the stimulus stands: Why recent challenges fail. En M. Piatelli \& R. Berwick (Eds.), Rich Languages from Poor Inputs (19-42). Oxford: Oxford University Press.

Beteta, E. (2003). Neurogenética de las funciones cognitivas. Revista de Neuro-Psiquiatría, 66, 335-343.

Broca, P. (1861). Perte de la parole, ramollissement chronique et destruction partielle du lobe antérieur gauche du cerveau. Bulletin et Memoires de la Societe d'Anthropologie, 2, 235-238.

Changeux, J. (1980). Genetic determinism and epigenesis of the neuronal network: Is there a biological compromise between Chomsky and Piaget. En M. Piattelli-Palmarini (Ed.), Language and learning. The debate between Jean Piaget and Noam Chomsky (pp.184-202). Cambridge: Harvard University Press. 
Chomsky, N. (1957). Syntactic Structure. London: Mouton.

Chomsky, N. (1959). A review of BF Skinner's Verbal Behavior. Language, $35(1), 26-58$.

Chomsky, N. (1965). Aspects of theory of syntax, Cambridge: MIT Press.

Chomsky, N. (1975). Reflections on Language. New York: Pantheon Books.

Chomsky, N. (1980). On cognitive structures and their development: A reply to Piaget. En M. Piattelli-Palmarini (Ed.), Language and learning. The debate between Jean Piaget and Noam Chomsky (pp.35-54). Cambridge: Harvard University Press.

Chomsky, N. (1985). El conocimiento del lenguaje. Su naturaleza, origen y uso. Madrid: Altaya.

Chomsky, N. (1995). The minimalist program. Cambridge: MIT Press.

Craik, K. (1943). The nature of explanation. Cambridge: Cambridge Press

Croft, W. \& Cruse, D. (2008). Lingüística Cognitiva. Madrid: Akal.

Cuenca, M. \& Hilferty, J. (1999). Introducción a la lingüística cognitiva. Barcelona: Ariel.

Damasio, A. (1994). El error de Descartes. Barcelona: Grijalbo.

Darwin, C. (1859/1970). El origen de las especies. Madrid: EDAF.

De la Barrera, M., Donolo, D. \& Rinaudo, M. (2010). Riesgo de demencia y niveles de educación: Cuando aprender es más saludable de lo que pensamos. Anales de Psicología, 26(1), 34-40.

De Vega, M. (2005). Lenguaje, corporeidad y cerebro: Una revisión crítica. Revista Signos, 38(58), 157-176.

Domingo, J. (2003). El proyecto modular de Jerry Fodor. Journal of psychology, 34(4), 564-573.

Eguren, L. \& Fernández, O. (2003). Introducción al programa minimalista. Madrid: Ariel.

Evans, V. \& Greens, M. (2006). Cognitive linguistics: An introduction. Efinburgh: Edinburgh UP. 
Fauconnier, G. \& Turner, M. (1998). Conceptual integration networks. Cognitive science, 22(2), 133-187.

Fernández-Jaén, J. (2010). EL problema del origen del lenguaje desde el punto de vista de la lingüística cognitiva. Estudios de lingüística, 24, 363-379.

Fierro, M. (2011). El desarrollo conceptual de la ciencia cognitiva. Revista Colombiana de Psiquiatría, 40(3), 519-533.

Fiske, S., \& Taylor, S. (1991). Social cognition. Nueva York: McGraw-Hill.

Fitch, W., Hauser, M. \& Chomsky, N. (2005). The evolution of the language faculty: Clarifications and implications. Cognition, 97(2), 179-210.

Fodor, J. (1983). The modularity of mind: An essay on faculty psychology. MIT Press.

Foucault, M. (2005). El poder psiquiátrico. Madrid: Akal.

Freberg, L. (2010). Discovering biological psychology. Belmont: Warworth.

Froufe, M. (2011). Psicología del aprendizaje. Principios y aplicaciones conductuales. Madrid: Paraninfo.

Geeraerts, D. (2006). Cognitive linguistics: Basic Reading. Berlin: Mouton.

Gomila, A. (2009). Cambio de marcha en la ciencia cognitiva: Cognición corpórea. Ciencias Cognitivas, 3(2), 49-51.

González, J. (2006). La cognición como objeto de estudio filosófico y científico. En J. González (Ed.), Perspectivas contemporáneas sobre la cognición: percepción, categorización y conceptualización (pp.11-39). Madrid: Siglo XXI.

Hauser, M., Chomsky, N. \& Fitch, W. (2002). The faculty of language: What is it, who has it, and how did it evolve? Science, 298(5598), 1569-1579.

Hernández-Piña, M. (1980). Las relaciones entre pensamiento según Piaget, Vygotsky. Anales de la Universidad de Murcia. Filosofía y Letras, 34(7), 69-90. 
Hilferty, J. (1993). Semántica lingüística y cognición. Verba, 20, 29-44.

Hilferty, J \& Vilarroya, O. (2002). ¿Podrían los genes codificar la gramática? Quark: Ciencia, Medicina, Comunicación y Cultura, 25, 35-44.

Ibarretxe, I. \& Valenzuela, J. (2012). Lingüística cognitiva: origen, principios teóricos y metodológicos, tendencias. En I. Ibarretxe \& J. Valenzuela (Coords.), Lingüística cognitiva (pp. 13-38). Barcelona: Antropos.

Itzigsohn, J. (1995). Prólogo. En L. Vygotsky. Pensamiento y lenguaje. Barcelona: Fausto.

Johnson, M. (1987). The body in the mind. Chicago: University Of Chicago Press.

Kolb, B. \& Whishaw, Q. (2009). Neuropsicología humana. Madrid: Panamericana.

Kövacses, Z. \& Radden, G. (1998). Metonymy: Developing a cognitive linguistic view. Cognitive Linguistic. 9(1), 37-77.

Lakoff, G. (1987). Women, fire, and dangerous things: What categories reveal about the mind. Chicago: University Press.

Lakoff, G. \& Johnson, M. (1980). Metaphors we live by. Chicago: University of Chicago Press.

Lakoff, G \& Johnson, M. (1999). Philosophy in the Flesh: The Embodied Mind and Its Challenge to Western Thought. NuevaYork: Basic Books.

Langacker, R. (1987). Foundations of cognitive grammar: Theoretical prerequisites. Stanford: Stanford University Press.

Lorenzo, G. (2009). Darwin y la facultad (no tan) humana del lenguaje. Ludus Vitalis, 17(32), 361-372.

Lucci, M. (2006). La propuesta de Vygotsky: la psicología socio-histórica. Profesorado: Revista de Curriculum y Formación del Profesorado, 10(2),10.

Medina, C. (2008). La ciencia cognitiva y el estudio de la mente. Revista de Investigación en Psicología, 11(1), 183-198. 
Mithen, S. (1996). La arqueología de la mente. Barcelona: Crítica.

Piaget, J. (1923). Language and Thought of the child. London: Reuter \& Kegan Paul.

(1924). Judgement and reasoning in the child. London: Reuter \& Kegan Paul.

. (1961). La formación del símbolo en el niño. México: Fondo de Cultura Económica.

Pinker, S. (1995). El instinto del lenguaje. Cómo crea el lenguaje la mente. Madrid: Alianza Editorial.

Pinker, S. \& Jackendoft , R. (2005). The faculty of language: what's special abaut it? Elsevier, 95, 201-236.

Pons, X. (2013). ¿Hay vida más allá del cognitivismo? Encontrando respuestas en la psicología social. Información Psicológica,105, 110-129.

Purves, D., Agustines, G., Fitzpatrick, D., Katz, L., Lamantia, A. \& McNamara, J. (2001). Invitación a la Neurociencia. Buenos Aires: Panamericana.

Rodríguez-Consuegra, F. (2004). Cognitivismo y lenguaje: ¿ Un paradigma que se hunde? Diálogos, 39(84), 7-50.

Sagan, C. (1981): El cerebro de Broca. Barcelona: Grijalbo

Stromswold, K. (2008). The genetics of speech and language impairments. New England Journal of Medicine, 359(22), 2381-2383.

Talmy, L. (1988). Force dynamics in language and cognition. Cognitive Science, 12(1), 49-100.

Thagard, P. (2008). La mente: Introducción a las ciencias cognitivas. Madrid: Katz.

Turner, M. (1990). Aspects of the invariance hypothesis. Cognitive Linguistics, 1(2), 247-255.

Turner, M. (1994). Design for a theory of meaning. En W. Overton \& D. Palermo(Eds.), The nature and ontogenesis of meaning (pp. 91-107). New Jersey: Lawrence Erlbaum. 
Valenzuela, J., Ibarretxe, I., \& Hilferty, J. (2012). La semántica cognitiva. En I. Ibarretxe \& J. Valenzuela (Coords.), Lingüística cognitiva (pp.41-68). Barcelona: Antropos.

Varela, F. (1989). Le corpus évocateur: une relecture de l'inmunité. Nouvelle Revue de Psychanalyse, 40(1), 193-213.

. (1996). Neurophenomenology: A methodological remedy to the hard problem. Journal of Consciousness Studies, 3(4), 330-350.

. (2001). El fenómeno de la vida. Chile: J.C.Sáez.

Varela, F., Thompson, E. \& Rosch, E. (1991) The Embodied Mind: Cognitive Science and Human Experience. Cambridge: MIT Press.

Vygotsky, L. (1929). El Desarrollo de las funciones psíquicas superiores. Barcelona: Crítica. . ([1934]1995). Pensamiento y lenguaje. Barcelona: Fausto.

Wilson, M. (2002). Six views of embodied cognition. Psychonomic Bulletin E Review, 9(4), 625 - 636.

Weerth, R. (1998). La PNL y la imaginación. Málaga: Sirio.

Wong, K. (2005). La aparición de la mente moderna. Ciertos hallazgos polémicos señalan que las raíces de nuestra inteligencia son mucho más profundas en el tiempo de lo que se pensaba. Investigación y Ciencia, 347, 76-85.

Zapata, L. (2009). Evolución, cerebro y cognición. Psicología desde el Caribe: Revista del Programa de Piscología de la Universidad del Norte,24, 106-119. 